\title{
Unimolecular decomposition of formic and acetic acids: a shock tube / laser absorption study
}

\author{
A. Elwardany, E.F. Nasir, Et. Es-sebbar, A. Farooq* \\ Clean Combustion Research Centre, Division of Physical Sciences and Engineering, \\ King Abdullah University of Science and Technology (KAUST), Thuwal 23955-6900, \\ Saudi Arabia
}

*Corresponding author, email: aamir.farooq@kaust.edu.sa, Tel: +966128082704

Colloquium: Chemical kinetics

$\begin{array}{ll}\text { Method of word count } & \text { Method 1 } \\ \text { Total length of paper } & 5591 \\ \text { Main text } & 3196 \text { (by Microsoft Word count) } \\ \text { Equations } & 304 \text { (recommended algebraic expression) } \\ \text { References } & 507 \text { (recommended algebraic expression) } \\ \text { Tables } & \text { NA } \\ \text { Figures } & 1584 \text { (reduced to production size and algebraic expression) } \\ \text { Figure 1 } & 360 \text { single column } \\ \text { Figure 2 } & 183 \text { single column } \\ \text { Figure 3 } & 180 \text { single column } \\ \text { Figure 4 } & 285 \text { single column } \\ \text { Figure 6 } & 285 \text { single column } \\ \text { Figure 6 } & 288 \text { single column } \\ \text { Abstract } & 288\end{array}$




\section{Abstract}

The thermal decomposition of formic acid $(\mathrm{HCOOH})$ and acetic acid $\left(\mathrm{CH}_{3} \mathrm{COOH}\right)$, two carboxylic acids which play an important role in oxygenate combustion chemistry, were investigated behind reflected shock waves using laser absorption. The rate constants of the primary decomposition pathways of these acids:

$$
\begin{gathered}
\mathrm{HCOOH} \rightarrow \mathrm{CO}+\mathrm{H}_{2} \mathrm{O} \\
\mathrm{HCOOH} \rightarrow \mathrm{CO}_{2}+\mathrm{H}_{2} \\
\mathrm{CH}_{3} \mathrm{COOH} \rightarrow \mathrm{CH}_{4}+\mathrm{CO}_{2} \\
\mathrm{CH}_{3} \mathrm{COOH} \rightarrow \mathrm{CH}_{2} \mathrm{CO}+\mathrm{H}_{2} \mathrm{O}
\end{gathered}
$$

were measured using simultaneous infrared laser absorption of $\mathrm{CO}, \mathrm{CO}_{2}$ and $\mathrm{H}_{2} \mathrm{O}$ at wavelengths of $4.56,4.18$ and 2.93 microns, respectively. Reaction test conditions covered temperatures from 1230 to $1821 \mathrm{~K}$ and pressures from 1.0 to $6.5 \mathrm{~atm}$ for dilute mixtures of acids $(0.25-0.6 \%)$ in argon. The rate constants of dehydration (R1) and decarboxylation (R2) reactions of formic acid were calculated by fitting exponential functions to the measured $\mathrm{CO}$, $\mathrm{CO}_{2}$ and $\mathrm{H}_{2} \mathrm{O}$ time-history profiles. These two decomposition channels were found to be in the fall-off region and have a branching ratio, $k_{1} / k_{2}$, of approximately 20 over the range of pressures studied here. The best-fit Arrhenius expressions of the first-order rates of R1 and R2 were found to be:

$$
\begin{gathered}
k_{1}(1 \mathrm{~atm})=1.03 \times 10^{11} \exp (-25651 / T) \mathrm{s}^{-1}( \pm 37 \%) \\
k_{1}(6.5 \mathrm{~atm})=9.12 \times 10^{12} \exp (-30275 / T) \mathrm{s}^{-1}( \pm 32 \%) \\
k_{2}(1 \mathrm{~atm})=1.79 \times 10^{8} \exp (-21133 / T) \mathrm{s}^{-1}( \pm 41 \%) \\
k_{2}(6.5 \mathrm{~atm})=2.73 \times 10^{8} \exp (-20074 / T) \mathrm{s}^{-1}( \pm 37 \%)
\end{gathered}
$$


The rate constants for acetic acid decomposition were obtained by fitting simulated profiles, using an acetic acid pyrolysis mechanism, to the measured species time-histories. The branching ratio, $k_{4} / k_{3}$, was found to be approximately 2 . The decarboxylation and dehydration reactions of acetic acid appear to be in the falloff region over the tested pressure range:

$$
\begin{gathered}
k_{3}(1 \mathrm{~atm})=3.18 \times 10^{11} \times \exp (-28679 / T) \mathrm{s}^{-1}( \pm 30 \%) \\
k_{3}(6 \mathrm{~atm})=3.51 \times 10^{12} \times \exp (-31330 / T) \mathrm{s}^{-1}( \pm 26 \%) \\
k_{4}(1 \mathrm{~atm})=7.9 \times 10^{11} \exp (-29056 / T) \mathrm{s}^{-1}( \pm 34 \%) . \\
k_{4}(6 \mathrm{~atm})=6.34 \times 10^{12} \times \exp (-31330 / T) \mathrm{s}^{-1}( \pm 31 \%) .
\end{gathered}
$$

Keywords:

Formic acid; acetic acid; shock tube; laser absorption; rate constants. 


\section{Introduction}

Carboxylic acids are compounds which contain one or more carboxyl groups $(\mathrm{COOH})$. They are readily formed during the pyrolysis and oxidation of large oxygenated species. This is particularly important in the modelling of ester-based bio-diesel fuels as carboxylic acids and ketenes are the main products of the pyrolysis of esters [1]. Formic acid $(\mathrm{HCOOH})$ has been shown to be the main product of ethyl formate pyrolysis [2] and acetic acid $\left(\mathrm{CH}_{3} \mathrm{COOH}\right)$ was observed to be a primary product of ethyl acetate decomposition $[2,3]$. Formic acid is also an important intermediate during the oxidation of dimethyl ether at low and intermediate temperatures [1] and acetic acid is the major product of acetic anhydride pyrolysis $[4,5]$. Accurate rate constant data describing the pyrolysis of formic and acetic acids are needed to build reliable kinetic mechanisms for large oxygenated fuels.

There are two main pathways for the decomposition of formic acid [6]; dehydration (R1), and decarboxylation (R2):

$$
\begin{aligned}
& \mathrm{HCOOH} \rightarrow \mathrm{CO}+\mathrm{H}_{2} \mathrm{O} \\
& \mathrm{HCOOH} \rightarrow \mathrm{CO}_{2}+\mathrm{H}_{2}
\end{aligned}
$$

A number of experimental [6-11] and theoretical [12-15] studies have been carried out on the decomposition of formic acid, including three shock tube studies. Hsu et al. [6] studied the decomposition of formic acid using infrared (IR) laser absorption of CO. They determined the rate constants of both reactions R1 and R2 using a non-linear least square fitting of the measured CO profiles. They found that the branching ratio, $k_{1} / k_{2}$, was $\sim 10$ at low temperatures and approaches 1 at $2000 \mathrm{~K}$. Saito et al. [7] studied the thermal decomposition of formic acid in a shock tube using formic acid emission near $3.4 \mu \mathrm{m}, \mathrm{CO}$ emission near $4.6 \mu \mathrm{m}$ and $\mathrm{CO}_{2}$ emission near $4.23 \mu \mathrm{m}$. Their measurements found that the branching ratio, $k_{1} / k_{2}$, was of order 100 over 
the entire temperature range (1300-2000 K). The observed rate constant behaviour agreed with their calculations using the Rice-Ramsperger-Kassel-Marcus (RRKM) weak collision theory. In 2005, Saito et al. [8] reinvestigated the decomposition of the formic acid by monitoring the IR emission of formic acid monomer $(5.66 \mu \mathrm{m}), \mathrm{CO}(4.63 \mu \mathrm{m})$ and $\mathrm{CO}_{2}(4.23 \mu \mathrm{m})$. They noted that $10-20 \%$ of gaseous formic acid is converted to formic acid dimer, $(\mathrm{HCOOH})_{2}$, at room temperature and this concentration cannot be neglected. Rate constant results obtained from this study were in reasonable agreement with their previous study [7].

Similar to formic acid, there are two main pathways for the decomposition of acetic acid; decarboxylation (R3) and dehydration (R4):

$$
\begin{gathered}
\mathrm{CH}_{3} \mathrm{COOH} \rightarrow \mathrm{CH}_{4}+\mathrm{CO}_{2} \\
\mathrm{CH}_{3} \mathrm{COOH} \rightarrow \mathrm{CH}_{2} \mathrm{CO}+\mathrm{H}_{2} \mathrm{O}
\end{gathered}
$$

Blake and Jackson $[16,17]$ studied the acetic acid pyrolysis using static and flow systems at temperatures of $733-1053 \mathrm{~K}$ and pressures near 1 atm. They concluded that the decarboxylation reaction is first order while the dehydration reaction is second order below 873 $\mathrm{K}$ and it exhibits first order behaviour for higher temperatures. Mackie and Doolan [18] studied the thermal decomposition of acetic acid in a single-pulse shock tube. Using gas chromatograph and IR cell analysis of the product gases, they found that the acetic acid decomposed through the two competing pathways, R3 and R4, at approximately equal rates and both rates were first order. Saito et al. [3] used a shock tube to study the thermal decomposition of ethyl acetate which produces acetic acid and ethylene. The branching ratio, $k_{4} / k_{3}$, was measured by comparing the monitored IR emissions from $\mathrm{CO}_{2}(4.23 \mu \mathrm{m})$ and $\mathrm{H}_{2} \mathrm{O}(2.68 \mu \mathrm{m})$ and was found to be approximately unity. Another study by Butkovskaya et al. [19] used a flow reactor and IR emission of $\mathrm{CO}_{2}$ and $\mathrm{H}_{2} \mathrm{O}$ to study acetic acid decomposition. They concluded that the $k_{4} / k_{3}$ 
ratio was two and in agreement with the ab-initio calculations of Nguyen et al. [20] and Duan and Page [21].

In this work, sensitive and time-resolved laser-absorption measurements of $\mathrm{CO}, \mathrm{CO}_{2}$ and $\mathrm{H}_{2} \mathrm{O}$ were used to study the thermal decomposition of formic and acetic acids behind reflected shock waves. The measured time-history profiles were then used to calculate the rate constants of dehydration and decarboxylation reactions for both acids and these rates are compared to available experimental and theoretical data.

\section{Experimental details}

\subsection{Shock tube facility}

The experiments were carried out in a high-purity stainless steel shock tube facility at King Abdullah University of Science and Technology (KAUST). The shock tube has an inner diameter of $14.2 \mathrm{~cm}$; the driven section is $9 \mathrm{~m}$ long while the driver section length can be varied to a maximum of $9 \mathrm{~m}$. The inner surface of the shock tube is honed and electro-polished to reduce boundary layers and trapped impurities. The incident shock velocity is determined $( \pm$ 0.1\%) using five PCB (Model 113B26) piezo-electric pressure transducers (PZT) spaced over the last 1.3 meters of the driven section. The shock velocity at the endwall is determined by extrapolating the measured velocity. Typical incident shock attenuation rates ranged from 0.2 to $2 \% / \mathrm{m}$ for the current experiments. The pre-shock mixture pressure, $\mathrm{P}_{1}$, is measured using a high-accuracy Baratron pressure transducer, while the pre-shock initial mixture temperature, $\mathrm{T}_{1}$, is measured using a K-type thermocouple. Reflected shock conditions, $\mathrm{P}_{5}$ and $\mathrm{T}_{5}$, are calculated using standard normal-shock relations and thermochemical data taken from the Sandia thermodynamic database [22]. 


\subsection{Mixture preparation}

Gas mixtures were prepared manometrically using high-purity argon (99.999\%) and Sigma Aldrich's formic $(\geq 98 \%)$ or acetic $(\geq 99.7 \%)$ acids. A freeze-pump-thaw process was used to purify the acids. The acid was first evaporated and introduced into a mixing vessel; argon gas was then slowly flown into the vessel. A magnetically-driven stirrer assembly was used for at least 1 hour ensure homogenous mixing. The shock tube was pumped for about 30 minutes between two successive experiments by a turbo-molecular pump (Varian TV 551), and achieved an ultimate pressure of $2 \times 10^{-5}$ mbar with out-gassing leak rate of $5 \times 10^{-6} \mathrm{mbar} / \mathrm{min}$.

Since formic and acetic acids tend to adsorb to the surface of shock tube and mixing vessel, Fourier-Transform-Infrared (FTIR) spectroscopy was used to measure the mole fraction of formic/acetic acid in the shock tube prior to the shock-heating process. A multi-pass optical cell, having an effective path-length of $190 \mathrm{~cm}$, was connected to the shock tube driven section through a valve and Teflon pipe. The pre-shock mixture was analyzed with an FTIR spectrometer (VETEX-80V) at a spectral resolution of $0.6 \mathrm{~cm}^{-1}$. The sample compartment of the spectrometer was purged with $\mathrm{N}_{2}$ to reduce interference absorption from ambient $\mathrm{CO}_{2}$ and water vapor. The FTIR setup used here has been described previously [23].

Both formic and acetic acids exhibit strong absorption bands near $1105\left(v_{6}\right)$ and $1182 \mathrm{~cm}^{-}$

${ }^{1}\left(v_{8}\right)$, as shown in Fig. S1 (Supplementary Material). Formic and acetic acid dimers also have strong absorption features near 1218 and $1295 \mathrm{~cm}^{-1}$, respectively (Fig. S1). Pure formic and acetic acid vapours can contain substantial $(\sim 30-50 \%)$ concentration of dimer. The dimer concentration is relatively small in mixtures of acid with argon, as used here. However, it is important to take the dimer concentration into consideration when calculating the initial acid 
mole fraction. The shock-heating process will convert all dimer to monomer at the reflected shock wave (time zero).

In the current work, the mole fractions of the acid monomers and dimers in the initial mixture were obtained by comparing the FTIR-measured integrated band intensities with values derived from PNNL database [24]. Our measurements indicate that the contribution of the dimer is quite small compared to monomer in the acid/argon mixtures used here; the dimer concentration is less than $10 \%$ in all considered cases. The initial concentration of the formic/acetic acid is calculated to be equal to monomer concentration $+2 \mathrm{x}$ dimer concentration. The mole fraction values obtained by FTIR spectroscopy are within $50 \%$ of the manometric values. Due to adsorption losses, the FTIR measured values are used for rate constant calculations.

\subsection{Laser absorption measurements}

Three separate optical setups were installed near the shock tube endwall to monitor simultaneously $\mathrm{CO}, \mathrm{CO}_{2}$, and $\mathrm{H}_{2} \mathrm{O}$ time-histories. The laser beams from three laser sources were transmitted through optical windows located at a distance $2 \mathrm{~cm}$ from the driven section endwall. For all absorption diagnostics, the mole fraction was calculated using the Beer-Lambert law:

$$
I / I_{0}=\exp \left(-S \phi X P_{5} L\right)
$$

where $I$ is the transmitted laser intensity, $I_{0}$ is the incident laser intensity, $S\left(\mathrm{~cm}^{-2} \mathrm{~atm}^{-1}\right)$ is the line-strength of the transition, $\phi(\mathrm{cm})$ is the line-shape function, $X$ is the mole fraction of the absorbing species, $P_{5}(\mathrm{~atm})$ is the total pressure of the gas behind reflected shock wave and $L$ (cm) is the absorption path length (internal diameter of the shock tube). 
Carbon monoxide mole fraction was measured using the $\mathrm{R}(13)$ absorption line near $2193.36 \mathrm{~cm}^{-1}(4.56 \mu \mathrm{m})$ in the $v_{1}$ fundamental vibrational band of CO. A fixed-wavelength direct absorption strategy was used, where the mid-IR light was generated by a cw quantum cascade laser (QCL) supplied by Alpes Lasers. The argon-broadening parameters for the $\mathrm{R}(13)$ transition were taken from [25], whereas line-strength was obtained from the HITRAN database [26].

An external-cavity QCL by Daylight Solutions was used for the laser absorption of carbon dioxide near $2390.52 \mathrm{~cm}^{-1}(4.18 \mu \mathrm{m})$ in the $v_{3}$ vibrational band of $\mathrm{CO}_{2}$. High temperature crosssections of $\mathrm{CO}_{2}$ at the line-centre were measured in our shock tube and verified with previous measurements by Ren et al. [27]. The time resolution of the laser diagnostics used in this study is 0.4 $\mu \mathrm{s}$.

Water vapour concentration was monitored using a distributed feedback (DFB) diode laser operating near $3416.16 \mathrm{~cm}^{-1}(2.93 \mu \mathrm{m})$ in the $v_{3}$ fundamental vibrational band of $\mathrm{H}_{2} \mathrm{O}$. The selected transition has relatively high lower-state energy and thus absorption by ambient water vapour is negligible. Absorption cross-sections were measured for the temperature range of interest using our shock tube facility.

\section{Results and discussion}

Unimolecular decomposition rates were measured for formic and acetic acids using shock tube and laser absorption. For formic acid, the experiments were performed at temperatures of $1234-1821 \mathrm{~K}$, pressures of 1.0 and $6.5 \mathrm{~atm}$ and initial concentration of $0.5 \%$ in argon. For acetic acid, the pyrolysis experiments were performed at temperatures of $1233-1853 \mathrm{~K}$, pressures of 1.0 and $6.0 \mathrm{~atm}$ and initial concentrations of $0.24 \%$ and $0.6 \%$ in argon. 


\subsection{Formic acid pyrolysis}

Concentration time-histories of $\mathrm{CO}, \mathrm{CO}_{2}$ and $\mathrm{H}_{2} \mathrm{O}$ were measured simultaneously during the pyrolysis of formic acid. Representative traces are shown in Fig. 1. The transmitted intensity is lost at early times due to the large density gradient across the shock wave, leading to a spike in the absorbance near time zero. This is known as the schlieren spike, not shown here. The rate constant, $k_{1}$, is calculated using three different approaches. The first and second approach are based on non-linear least square fitting (shown in Fig. 1) of the $[\mathrm{CO}]$ and $\left[\mathrm{H}_{2} \mathrm{O}\right]$ profiles, as suggested by Hsu et al. [6].

$$
[\mathrm{CO}]_{t}=a(1-\exp (-b t)),
$$

where $b=k_{1}+k_{2}, a=k_{1}[\mathrm{FA}]_{0} / b$. The constants $a$ and $b$ are derived from fits to the data. Knowing the initial concentration of formic acid, $[\mathrm{FA}]_{0}$, the first order rate constants, $k_{1}$ and $k_{2}$, can be calculated. The second order rate constants can be calculated using the total density. An equation, similar to Eq. (2), can also be written for $\mathrm{H}_{2} \mathrm{O}$. The rate constants calculated using $[\mathrm{CO}]$ and $\left[\mathrm{H}_{2} \mathrm{O}\right]$ profiles are within $8 \%$ of each other. The third approach is based on fitting the measured profiles using the Curran et al. [1] dimethyl ether mechanism which includes the pyrolysis reactions of formic acid. The measured $\mathrm{CO}$ time-history profiles were fit by changing $k_{1}$ to achieve a best-fit; Fig. 2 shows an example of fitting the CO profile with the mechanismsimulated profile.

A comparison between the values of $k_{1}$ calculated by fitting the [CO] profiles to exponential function (Eq. (2)) and by using the best-fit profiles from the mechanism [1] is shown in Fig. 3. Both methods agree reasonably with each other over the range of temperatures studied here. Similar behaviour was observed for the decarboxylation rate $k_{2}$ by comparing the rates 
obtained by exponential function and mechanism fitting of $\mathrm{CO}_{2}$ profiles. Sensitivity analyses were performed for $\mathrm{CO}$ and $\mathrm{CO}_{2}$ using Curran et al. [1] mechanism, and are shown in Figs. S2 and S3 (Supplementary Material). The sensitivity is calculated as $S=\left(\partial X / \partial k_{i}\right) \times\left(k_{i} / X\right)$, where $X$ is the local species mole fraction and $k_{i}$ is the rate constant of the $i^{\text {th }}$ reaction. The sensitivity plots show that the dehydration and decarboxylation reactions are dominant at the experimental conditions. However, minor interferences from secondary reactions occur and can become significant at higher temperatures and longer times. Therefore, at temperatures higher than 1500 $\mathrm{K}$, only the initial $50-100 \mu \mathrm{s}$ of the measured species profiles are used to deduce rate constants. The sensitivity analyses presented in Figs. S2 and S3 show the influence of a $3^{\text {rd }}$ decomposition channel, $\mathrm{HCOOH}=\mathrm{HCO}+\mathrm{OH}$. This is an energetically inaccessible channel and we think that the rate parameters for this reaction are overestimated in the kinetic mechanism used here and thus shows up being sensitive. This is another reason that we opted to not use the mechanismfitting method for deducing rate constants. Hsu et al. [6] also concluded that this reaction can be ignored and only R1 and R2 are the main decomposition pathways of formic acid.

Arrhenius plots of the rate constants, calculated based on Eq. (2) fitting, for reactions R1 and R2 are shown in Fig. 4. Excellent signal-to-noise ratio (SNR) was obtained for CO profiles at all cases, however, the $\mathrm{SNR}$ of the $\mathrm{CO}_{2}$ profiles was quite low. This is due to the fact that the branching ratio of formic acid decomposition strongly favours $\mathrm{CO}$ formation. The measured rate constants did not exhibit any dependence on the initial concentration of $\mathrm{HCOOH}$. It can be seen from Fig. 4 that both the dehydration reaction (R1) and the decarboxylation reaction (R2) are in the fall-off range over the measured pressure range $(1-6 \mathrm{~atm})$. We have, therefore, plotted the first-order rates of R1 and R2 at different pressures in Fig. 4. Experimental work of Saito et al. $[7,8]$ concluded that $k_{2}$ is in the fall-off region whereas $k_{1}$ is in the low-pressure limit over $1-5$ 
atm. Their RRKM calculations, on the other hand, predicted that both reactions should be in the falloff region over a pressure range of $1-12 \mathrm{~atm}$. Additional studies at higher pressures are needed to ascertain the fall-off behaviour of the formic acid decomposition reactions. Fitting the experimental data for $k_{1}$ and $k_{2}$ (balck ' 1.0 atm' and red ' 6.5 atm' lines in Fig. 4) results in the following first order rate constants:

$$
\begin{gathered}
k_{1}(1 \mathrm{~atm})=1.03 \times 10^{11} \exp (-25651 / T) \mathrm{s}^{-1}(1234-1596 \mathrm{~K}) \\
k_{1}(6.5 \mathrm{~atm})=9.12 \times 10^{12} \exp (-30275 / T) \mathrm{s}^{-1}(1283-1616 \mathrm{~K}) \\
k_{2}(1 \mathrm{~atm})=1.79 \times 10^{8} \exp (-21133 / T) \mathrm{s}^{-1}(1283-1616 \mathrm{~K}) \\
k_{2}(6.5 \mathrm{~atm})=2.73 \times 10^{8} \exp (-20074 / T) \mathrm{s}^{-1}(1234-1821 \mathrm{~K})
\end{gathered}
$$

Best-fit lines to the experimental data of Hsu et al. [6] and Saito et al. [7] are also shown in Fig. 4 for comparison with our data. For the rate constant of dehydration reaction (R1), there is good agreement between our $1 \mathrm{~atm}$ data and Saito et al. [7] data at temperatures less than 1430 $\mathrm{K}$, while at higher temperatures our measured rate constants are faster by a factor of $2-4$. The dehydration rate constant measured by Hsu et al. [6] is lower at all temperatures, though their activation energy is quite similar to our data. The current study exhibits less uncertainty because of the lower reactant concentration, and thus lower influence from secondary reactions, that was possible because of the sensitive laser absorption diagnostics for $\mathrm{CO}, \mathrm{CO}_{2}$ and $\mathrm{H}_{2} \mathrm{O}$. The rate constant for decarboxylation reaction (R2) provided by Saito et al. [7] is lower than that of Hsu et al. [6] by approximately two orders of magnitude. Our measurements fall between these two previous determinations. Comparing Fig. 4(a) and Fig. 4(b), it can be concluded that the $k_{1} / k_{2} \cong 20$ over the entire temperature range studied here. 


\subsection{Acetic acid pyrolysis}

Pyrolysis of acetic acid diluted in argon was studied at temperatures of 1233-1720 K, pressures of $1.0 \mathrm{~atm}$ and $6.0 \mathrm{~atm}$ and two initial concentrations of acetic acid $(0.24 \%$ and $0.5 \%$.) As mentioned earlier, acetic acid decomposes via decarboxylation (R3) and dehydration (R4) reactions. The rate constants, $k_{3}$ and $k_{4}$, of these two reactions were determined by fitting the measured $\mathrm{CO}_{2}$ and $\mathrm{H}_{2} \mathrm{O}$ profiles with simulations from the acetic acid mechanism of Mackie and Doolan [18]. Figure 5 shows representative time-history profiles of $\mathrm{CO}_{2}$ and $\mathrm{H}_{2} \mathrm{O}$ for the pyrolysis $\mathrm{CH}_{3} \mathrm{COOH}$. The best-fit profiles give a value of $438 \mathrm{~s}^{-1}$ for $k_{3}$ and $740 \mathrm{~s}^{-1}$ for $k_{4}$. This method of determining the rate constant by fitting the measured species profile with the simulated profile was prefered for acetic acid because the pyrolysis mechanism of Mackie and Doolan [18] contains all relevant reactions of acetic acid and its fragments. Sensitivity analyses performed for $\mathrm{CO}_{2}$ and $\mathrm{H}_{2} \mathrm{O}$ (Fig. S4 Supplementary Material) show that the $\mathrm{CO}_{2}$ profile is only significantly sensitive to the rate constant $k_{3}$, while the $\mathrm{H}_{2} \mathrm{O}$ profile is primarily sensitive to the rate constant $k_{4}$.

Arrhenius plots for both decarboxylation and dehydration reactions of acetic acid pyrolysis are shown in Fig. 6 for a range of pressures and initial concentrations. It can be observed that the first order rate constants of both reactions R3 and R4 show pressure dependence. Thus the decarboxylation and dehydration reactions (R3 and R4) appear to be in the falloff regime. Fitting the experimental data for $k_{3}$ and $k_{4}$ (red '1.0 atm' and green ' 6.0 atm' lines in Fig. 6) results in the following first order rate constants:

$$
\begin{gathered}
k_{3}(1 \mathrm{~atm})=3.18 \times 10^{11} \times \exp (-28679 / T) \mathrm{s}^{-1}(1233-1851 \mathrm{~K}) \\
k_{3}(6 \mathrm{~atm})=3.51 \times 10^{12} \times \exp (-31330 / T) \mathrm{s}^{-1}(1314-1714 \mathrm{~K}) \\
k_{4}(1 \mathrm{~atm})=7.9 \times 10^{11} \exp (-29056 / T) \mathrm{s}^{-1}(1233-1851 \mathrm{~K})
\end{gathered}
$$




$$
k_{4}(6 \mathrm{~atm})=6.34 \times 10^{12} \times \exp (-31330 / T) \mathrm{s}^{-1}(1314-1714 \mathrm{~K})
$$

Our measured rate constant data show that the tendency of the dehydration reaction to occur is about two times higher than that of the decarboxylation reaction, as observed previously by [19-21]. Mackie and Doolan [18], on the other hand, argued that both reactions have about the same probability. It can be also seen from Fig. 6 that there is reasonable agreement, especially at high temperatures, between our measured rate constants $\left(k_{3}\right.$ and $\left.k_{4}\right)$ and the theoretical values calculated by Duan and Page [21]. The experimental values measured by Mackie and Doolan [18] are smaller than our results by almost an order of magnitude.

\subsection{Uncertainty analysis}

Detailed uncertainty analysis is carried out to estimate the overall uncertainty in the measured rate constants. The individual sources of errors in the measured rate constants are: temperatures $( \pm 0.7 \%)$, the mixture composition $( \pm 50 \%), \mathrm{CO}, \mathrm{H}_{2} \mathrm{O}$ and $\mathrm{CO}_{2}$ absorption coefficients $\left( \pm 3 \%\right.$ ), wavemeter reading $\left( \pm 0.005 \mathrm{~cm}^{-1}\right)$, fitting the experimental profiles $( \pm 5 \%)$, locating time zero $( \pm 0.5 \mu \mathrm{s})$, the rate constants for secondary reactions $\mathrm{HCOOH} \rightarrow \mathrm{HCO}+\mathrm{OH}$ (uncertainty factor $=4, \mathrm{R} 1$ and $\mathrm{R} 2$ ), $\mathrm{HCOOH}+\mathrm{H} \rightarrow \mathrm{H}_{2}+\mathrm{CO}+\mathrm{OH}$ (uncertainty factor $=4, \mathrm{R} 1$ ), $\mathrm{HCOOH}+\mathrm{H} \rightarrow \mathrm{H}_{2}+\mathrm{CO}_{2}+\mathrm{H}$ (uncertainty factor $=4, \mathrm{R} 2$ ), $\mathrm{CH}_{3} \mathrm{COOH} \rightarrow \mathrm{CH}_{4}+\mathrm{CO}_{2}$ (uncertainty factor $=4, \mathrm{R} 4$ ) and $\mathrm{CH}_{3} \mathrm{COOH} \rightarrow \mathrm{CH}_{2} \mathrm{CO}+\mathrm{H}_{2} \mathrm{O}$ (uncertainty factor $=1.86, \mathrm{R} 4$ ). The effects of these error sources on the rate constant are determined separately. The overall uncertainty is calculated by the root-sum-squared method and found to be $\pm 37 \%$ and $\pm 41 \%$ for the first-order rate constants of R1 and R2, respectively at $1396 \mathrm{~K}$ and $1.22 \mathrm{~atm}$. The uncertainty was calculated to be $32 \%$ and $37 \%$ for $\mathrm{R} 1$ and $\mathrm{R} 2$ at $1353 \mathrm{~K}$ and $6.8 \mathrm{~atm}$. The estimated overall uncertainties of first-order rate for reactions $\mathrm{R} 3$ and $\mathrm{R} 4$ are $\pm 29 \%$ and $\pm 34 \%$, respectively at 
$1435 \mathrm{~K}$ and $0.964 \mathrm{~atm}$. It was also calculated at $1472 \mathrm{~K}$ and $6.2 \mathrm{~atm}$ and found to be $25 \%$ and $31 \%$ for R3 and R4, respectively.

\section{Conclusions}

The rate constants for the decarboxylation and dehydration pathways of formic and acetic acid pyrolysis were measured behind reflected shock waves using $\mathrm{CO}, \mathrm{CO}_{2}$ and $\mathrm{H}_{2} \mathrm{O}$ laser absorption. Significantly reduced uncertainties in these rate measurements were achieved because of the high sensitivity and signal-to-noise ratio of the species time-history measurements used in these determinations. The measured rate constants will help provide improved modelling of the decomposition of these two carboxylic acids and will aid in the refinement of detailed kinetic mechanisms of oxygen-containing biofuels.

\section{Acknowledgments}

This work was supported by Saudi Aramco under the FUELCOM program and by Clean Combustion Research Centre at King Abdullah University of Science and Technology (KAUST).

\section{Supplementary material}

Supplementary material provides representative FTIR measurements of formic and acetic acids initial concentrations, measured mole fraction of $\mathrm{CO}$ during the pyrolysis of formic acid and sensitivity analyses of $\mathrm{CO}, \mathrm{CO}_{2}$ and $\mathrm{H}_{2} \mathrm{O}$ during the pyrolysis of formic and acetic acids. 


\section{References}

1. H. Curran, S. Fischer, F. Dryer, Int. J. Chem. Kinet. 32 (12) (2000) 741-759.

2. A. T. Blades, Can. J. Chem. 32 (4) (1954) 366-372.

3. K. Saito, T. Sasaki, I. Yoshinobu, A. Imamura, Chem. Phys. Lett. 170 (4) (1990) 385388.

4. V. Vasudevan, Shock tube measurements of elementary oxidation and decomposition reactions important in combustion using $\mathrm{OH}, \mathrm{CH}$ and $\mathrm{NCN}$ laser absorption, $\mathrm{PhD}$ thesis, Stanford University, USA, 2007.

5. M. Akao, K. Saito, K. Okada, O. Takahashi, K. Tabayashi, Berichte der Bunsengesellschaft für physikalische Chemie 100 (7) (1996) 1237-1241.

6. D. S. Y. Hsu, W. M. Shaub, M. Blackburn, M. C. Lin, Proc. Combust. Inst. 19 (1) (1982) 89-96.

7. K. Saito, T. Kakumoto, H. Kuroda, S. Torii, A. Imamura, J, Chem. Phys. 80 (1984) 4989.

8. K. Saito, T. Shiose, O. Takahashi, Y. Hidaka, F. Aiba, K. Tabayashi, J. Phys. Chem. A 109 (24) (2005) 5352-5357.

9. P. G. Blake, H. H. Davies, G. E. Jackson, J. Chem. Soc. B: Phys. Org. (0) (1971) 19231925.

10. H. Su, Y. He, F. Kong, W. Fang, R. Liu, J, Chem. Phys. 113 (2000) 1891.

11. T. Ebata, A. Fujii, T. Amano, M. Ito, J. Phys. Chem. 91 (24) (1987) 6095-6097.

12. J. Francisco, J, Chem. Phys. 96 (1992) 1167.

13. J.-G. Chang, H.-T. Chen, S. Xu, M. Lin, J. Phys. Chem. A 111 (29) (2007) 6789-6797.

14. I. d. P. R. Moreira, J. Mol. Str: THEOCHEM 466 (1-3) (1999) 119-126. 
15. Y. Kurosaki, K. Yokoyama, Y. Teranishi, Chem. Phys. 308 (3) (2005) 325-334.

16. P. G. Blake, G. E. Jackson, J. Chem. Soc. B: Phys. Org. (0) (1968) 1153-1155.

17. P. G. Blake, G. E. Jackson, J. Chem. Soc. B: Phys. Org. 0 (0) (1969) 94-96.

18. J. C. Mackie, K. R. Doolan, Int. J. Chem. Kinet. 16 (5) (1984) 525-541.

19. N. Butkovskaya, G. Manke, D. Setser, J. Phys. Chem. 99 (28) (1995) 11115-11121.

20. M. T. Nguyen, D. Sengupta, G. Raspoet, L. G. Vanquickenborne, J. Phys. Chem. 99 (31) (1995) 11883-11888.

21. X. Duan, M. Page, J. Am. Chem. Soc. 117 (18) (1995) 5114-5119.

22. R. Kee, F. Rupley, J. Miller, The Chemical Thermodynamic Data Base, Report No. SAND87- 8215B.UC-4, Sandia National Laboratory, 1987.

23. E.-t. Es-sebbar, Y. Benilan, A. Farooq, J. Quant. Spectrosc. Radiat. Transfer 115 (2013) $1-12$.

24. S. W. Sharpe, T. J. Johnson, R. L. Sams, P. M. Chu, G. C. Rhoderick, P. A. Johnson, Appl. Spectrosc. 58 (12) (2004) 1452-1461.

25. W. Ren, A. Farooq, D. Davidson, R. Hanson, Appl. Phys. B 107 (3) (2012) 849-860.

26. L. Rothman, I. Gordon, Y. Babikov, A. Barbe, D. Chris Benner, P. Bernath, M. Birk, L. Bizzocchi, V. Boudon, L. Brown, J. Quant. Spectrosc. Radiat. Transfer 130 (2013) 4-50.

27. W. Ren, R. Spearrin, D. Davidson, R. Hanson, in: 8th U.S. National Combustion Meeting, University of Utah, USA, May, 2013. 



\section{Figures}
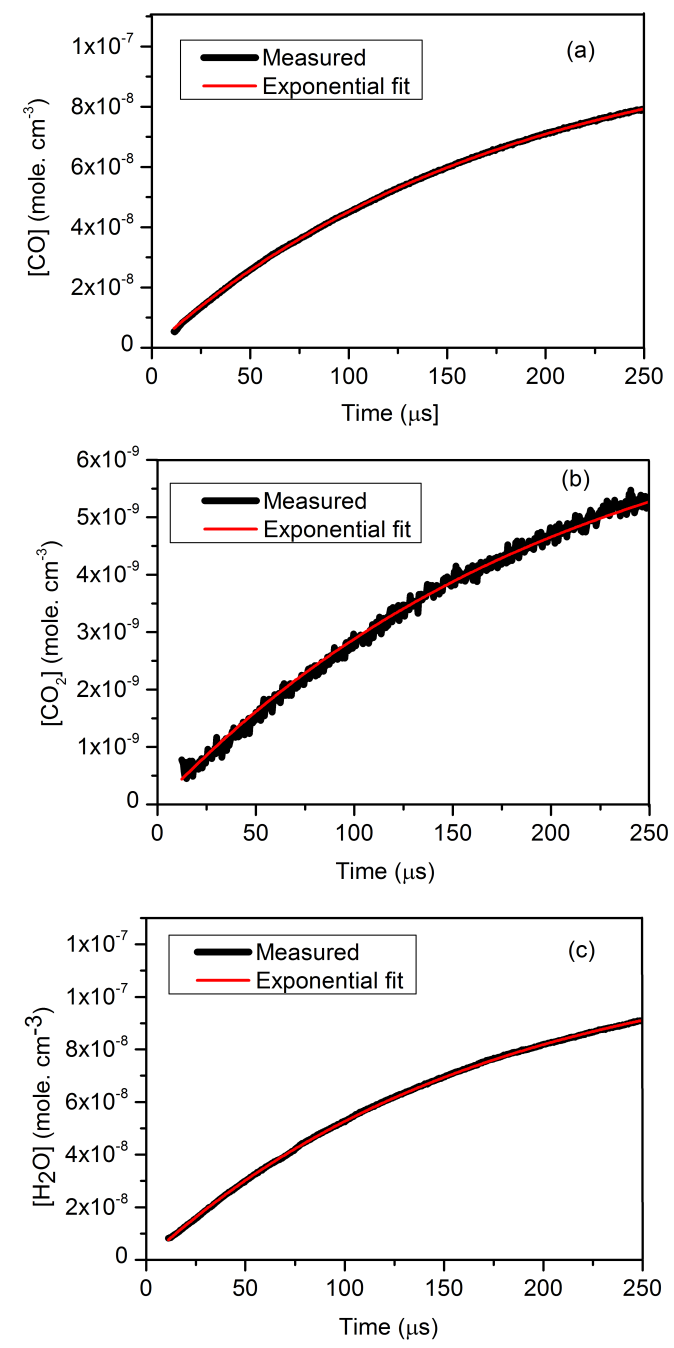

Fig. 1. Measured (a) $\mathrm{CO}$ (b) $\mathrm{CO}_{2}$ and (c) $\mathrm{H}_{2} \mathrm{O}$ concentrations profiles for the decomposition of $0.46 \%$ formic acid/Ar at $1532 \mathrm{~K}$ and $1.15 \mathrm{~atm}$. Also, shown are the best-fit profiles using the exponential function (Eq. (2)). 


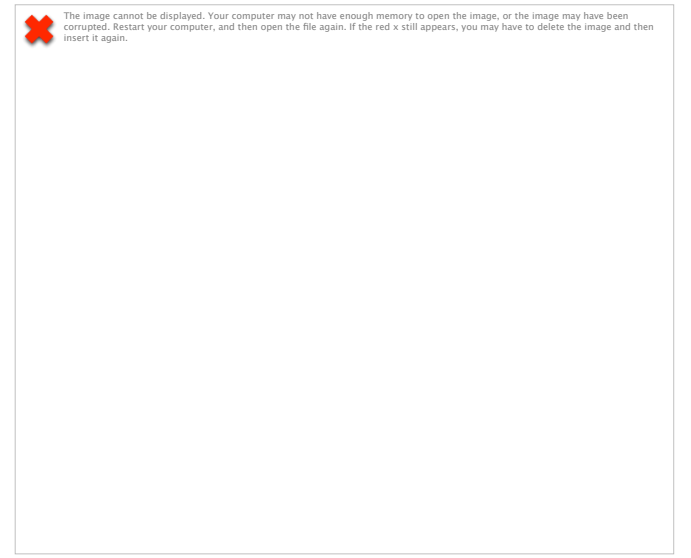

Fig. 2. Measured mole fraction of CO behind reflected shock waves for $0.37 \%$ formic acid/Ar pyrolysis at $1396 \mathrm{~K}$ and $1.22 \mathrm{~atm}$. Best-fit line using the kinetic mechanism as well as perturbations of $\pm 50 \%$ are also presented. 


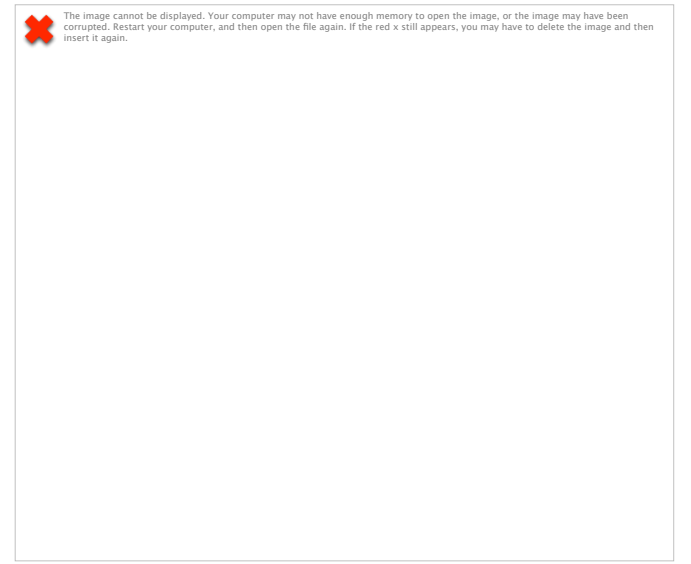

Fig. 3. Comparison of $k_{1}$ determined by fitting the $\mathrm{CO}$ profiles with an exponential function (Eq. (2)) and by using the best-fit profile from the kinetic mechanism. Solid lines are linear-fit to the data points. 

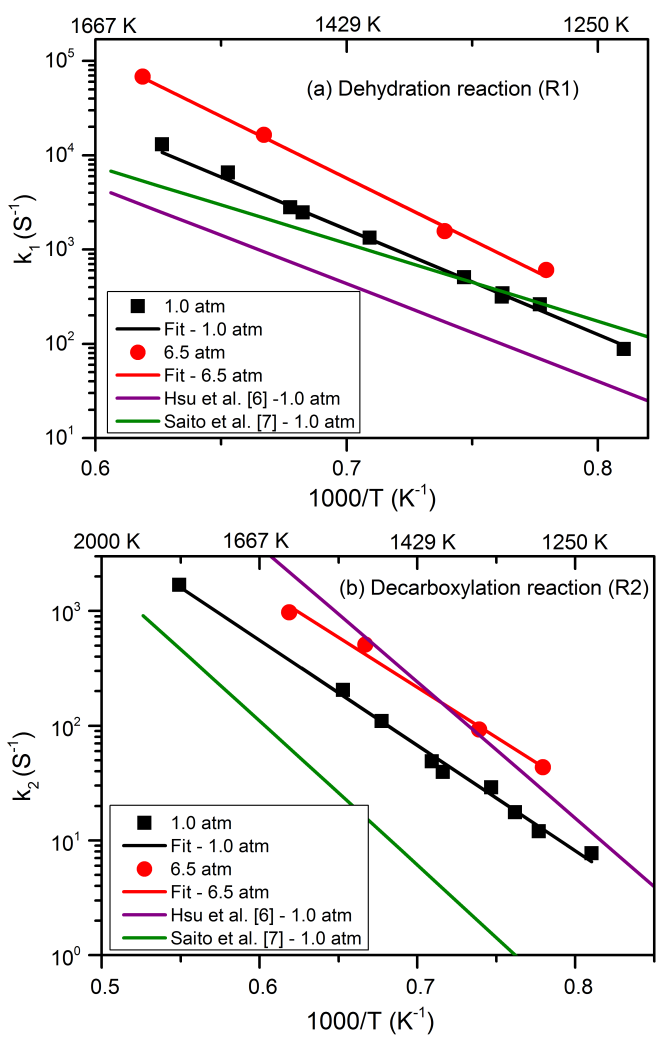

Fig. 4. Comparison of the measured (a) $k_{1}$ and (b) $k_{2}$ with previous experimental data. Formic acid concentration was $0.5 \%$ for both $1 \mathrm{~atm}$ and $6.5 \mathrm{~atm}$ cases. 

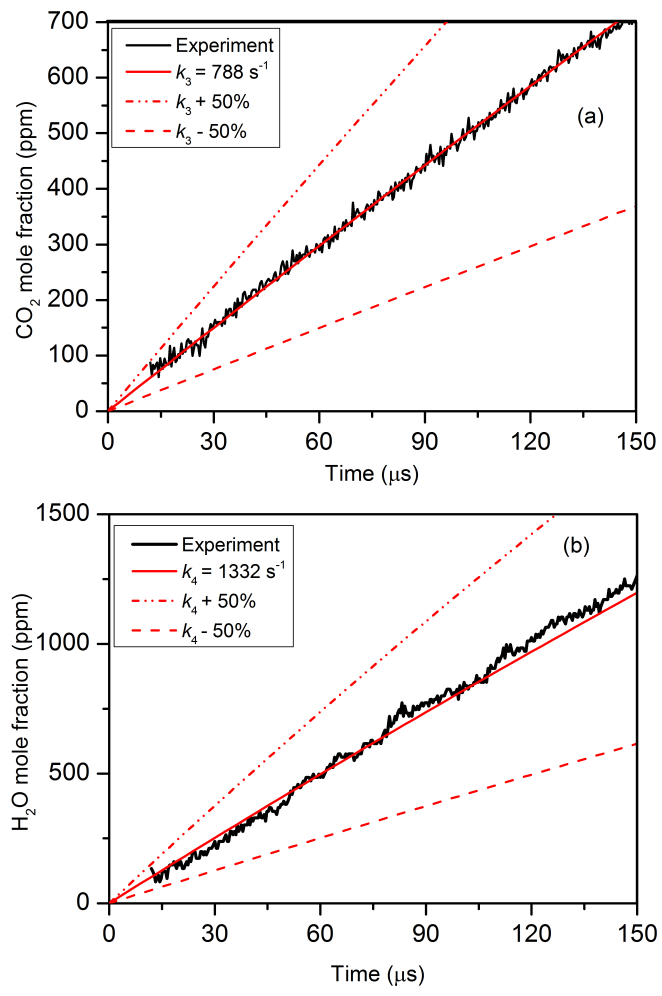

Fig. 5. Measured mole fractions of (a) $\mathrm{CO}_{2}$ and (b) $\mathrm{H}_{2} \mathrm{O}$ for $0.64 \%$ acetic acid/Ar pyrolysis at $1435 \mathrm{~K}$ and $0.964 \mathrm{~atm}$. Best-fit lines using the kinetic mechanism as well as perturbations of \pm $50 \%$ are also presented. 

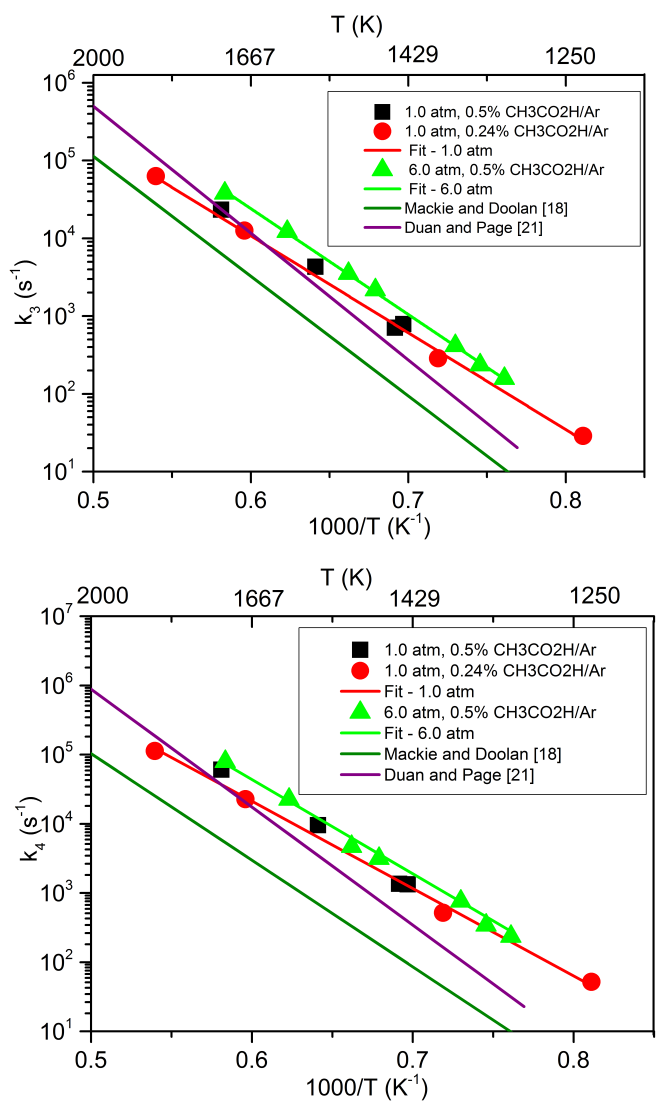

Fig. 6. Arrhenius plots of (a) $k_{3}$ and (b) $k_{4}$ at different conditions (shown in the figure) and comparison with previous studies. 


\section{Figure Captions}

Fig. 1. Measured (a) $\mathrm{CO}$ (b) $\mathrm{CO}_{2}$ and (c) $\mathrm{H}_{2} \mathrm{O}$ concentrations profiles for the decomposition of $0.46 \%$ formic acid/Ar at $1532 \mathrm{~K}$ and $1.15 \mathrm{~atm}$. Also, shown are the best-fit profiles using the exponential function (Eq. (2)).

Fig. 2. Measured mole fraction of CO behind reflected shock waves for $0.37 \%$ formic acid/Ar pyrolysis at $1396 \mathrm{~K}$ and $1.22 \mathrm{~atm}$. Best-fit line using the kinetic mechanism as well as perturbations of $\pm 50 \%$ are also presented.

Fig. 3. Comparison of $k_{1}$ determined by fitting the $\mathrm{CO}$ profiles with an exponential function (Eq. (2)) and by using the best-fit profile from the kinetic mechanism. Solid lines are linear-fit to the data points.

Fig. 4. Comparison of the measured (a) $k_{1}$ and (b) $k_{2}$ with previous experimental data. Two sets of mixtures were used; $1.0 \mathrm{~atm} / 0.5 \% \mathrm{HCOOH}$ and $6.5 \mathrm{~atm} / 0.5 \% \mathrm{HCOOH}$.

Fig. 5. Measured mole fractions of (a) $\mathrm{CO}_{2}$ and (b) $\mathrm{H}_{2} \mathrm{O}$ for $0.64 \%$ acetic acid/Ar pyrolysis at $1435 \mathrm{~K}$ and $0.964 \mathrm{~atm}$. Best-fit lines using the kinetic mechanism as well as perturbations of \pm $50 \%$ are also presented.

Fig. 6. Arrhenius plots of (a) $k_{3}$ and (b) $k_{4}$ at different conditions (shown in the figure) and comparison with previous studies. 


\title{
Unimolecular decomposition of formic and acetic acids: a shock tube / laser absorption study
}

\author{
A. Elwardany, E.F. Nasir, Et. Es-sebbar, A. Farooq
}

Supplementary Material; Proc. Combust. Inst. 35, 2015

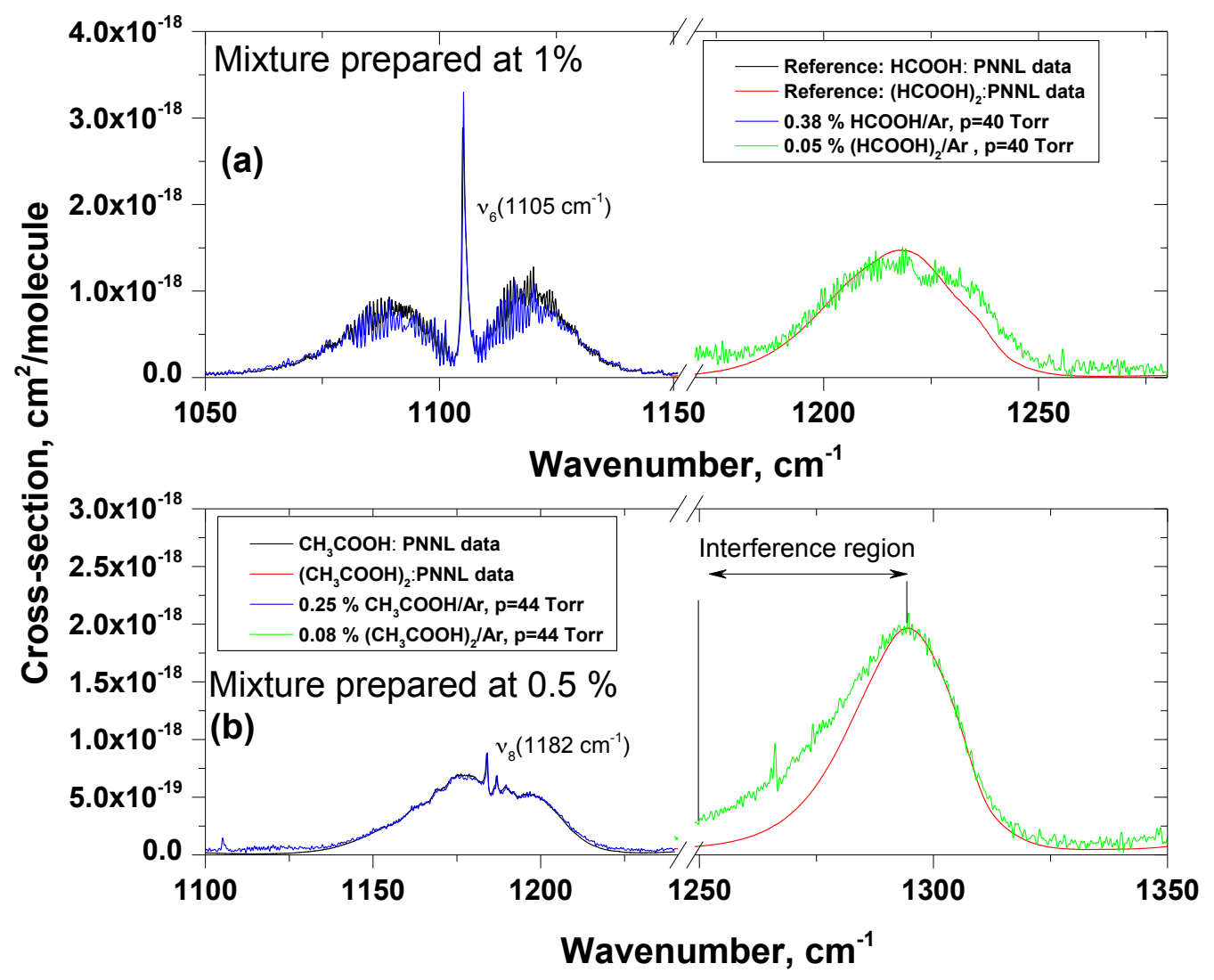

Fig. S1. Infrared cross-sections of (a) Formic acid and (b) Acetic acid measured by FTIR spectroscopy at spectral resolution of $0.6 \mathrm{~cm}^{-1}$. Features involving $v_{6}$ and $v_{8}$ of $\mathrm{C}-\mathrm{O}$ stretching mode are used for determination of the integrated intensities to deduce the mole fraction in the mixture. 

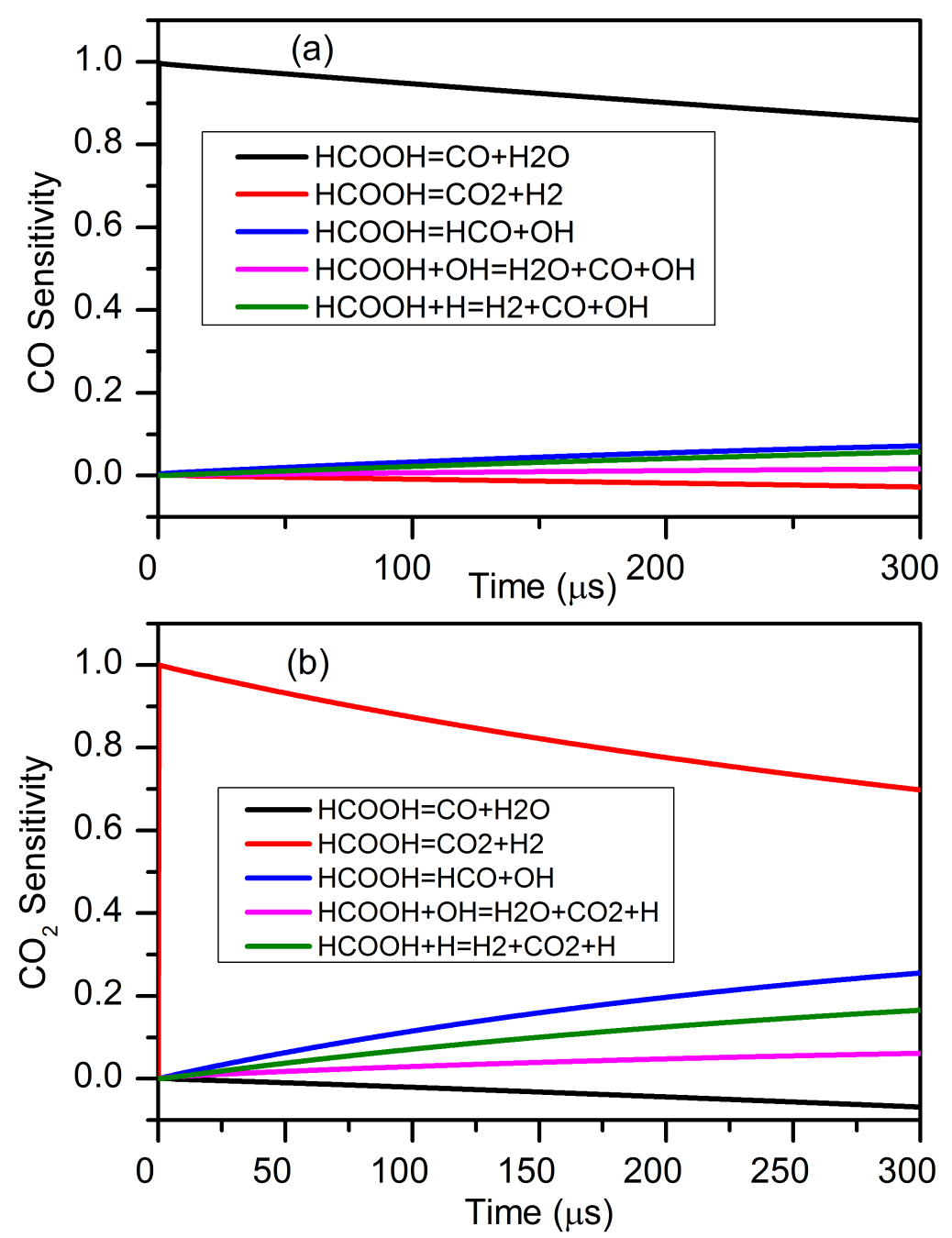

Fig. S2. Sensitivity analyses for (a) $\mathrm{CO}$ and (b) $\mathrm{CO}_{2}$ during the pyrolysis of $0.37 \% \mathrm{HCOOH} / \mathrm{Ar}$ at $1396 \mathrm{~K}$ and $1.22 \mathrm{~atm}$. 

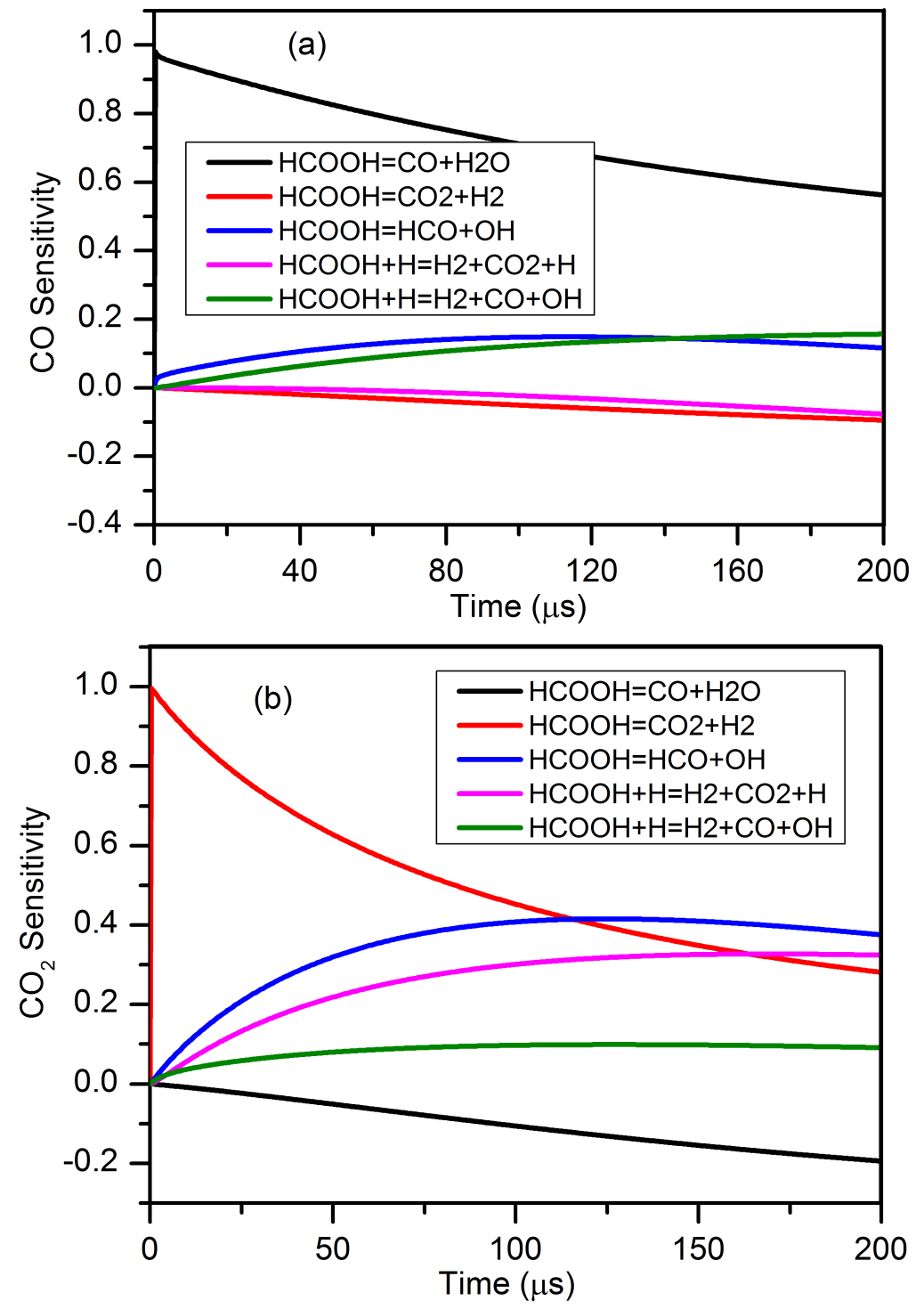

Fig. S3. Sensitivity analyses for (a) $\mathrm{CO}$ and (b) $\mathrm{CO}_{2}$ during the pyrolysis of $0.46 \% \mathrm{HCOOH} / \mathrm{Ar}$ at $1532 \mathrm{~K}$ and $1.15 \mathrm{~atm}$. 

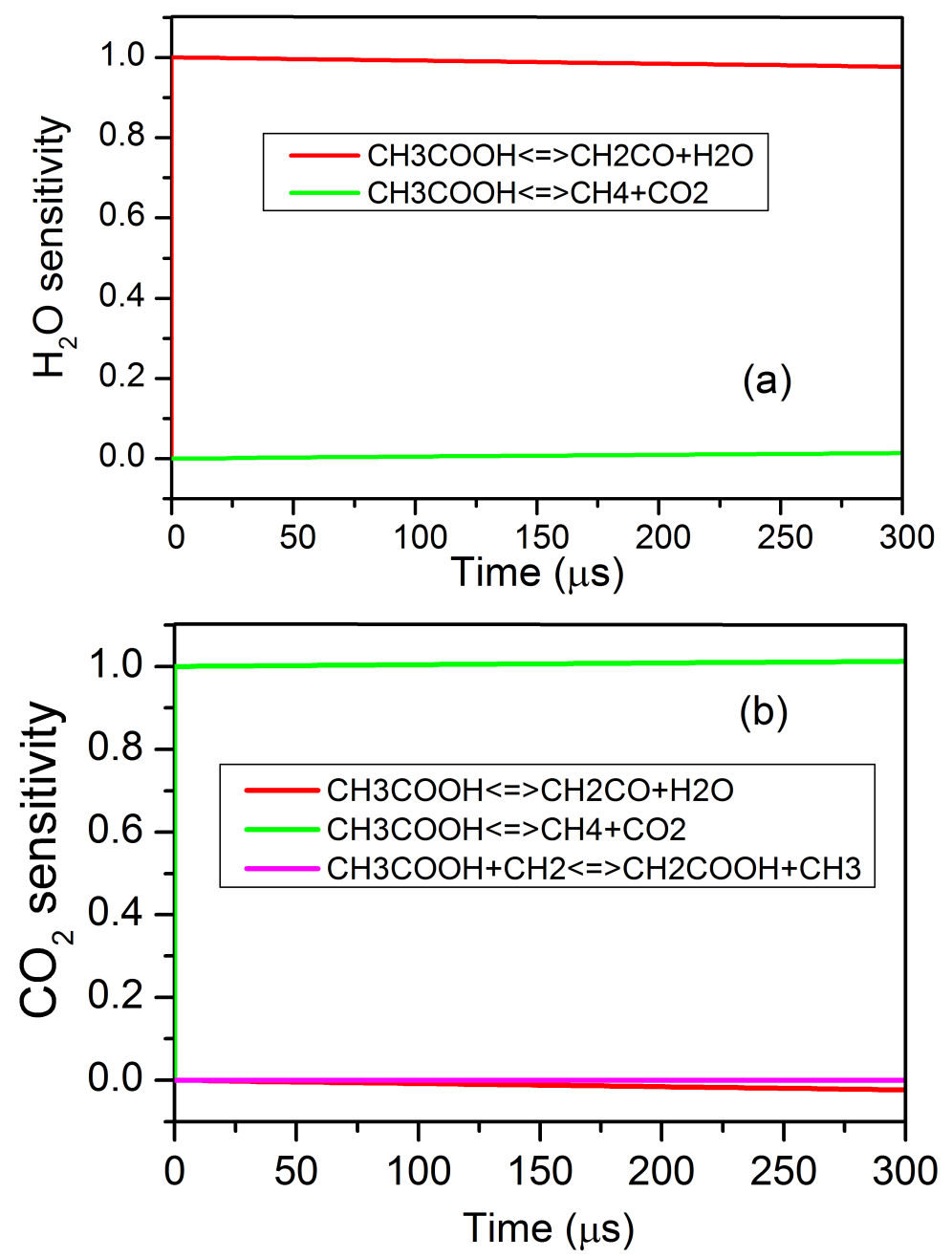

Fig. S4. Sensitivity analyses for (a) $\mathrm{CO}$ and (b) $\mathrm{CO}_{2}$ for pyrolysis of $0.64 \% \mathrm{CH} 3 \mathrm{COOH} / \mathrm{Ar}$ at $1435 \mathrm{~K}$ and $0.964 \mathrm{~atm}$. 